\title{
REVIEW
}

\section{Life expectancy in severe cerebral palsy}

\author{
J L Hutton, P O D Pharoah
}

Arch Dis Child 2006;91:254-258. doi: 10.1136/adc.2005.075002

Cerebral palsy comprises an important component of paediatric and obstetric practice and has major medicolegal implications. The prognosis for survival in cerebral palsy determines the financial provision made in cases that come to litigation. Issues of data quality and estimation methods are critical. Estimating the probability of survival in cerebral palsy based on clinical experience is liable to serious error unless numerical data can be produced. Only an actuarial analysis based on a standard life table of cases of cerebral palsy will enable a valid estimate of survival. Construction of the table requires a total cohort of cases of cerebral palsy with their date of birth. Each case must conform to a specified definition of the syndrome. Notification of all those who die, with their date of death is mandatory. Estimating the probability of survival according to the severity of functional disability requires specific definitional criteria for each severity category and for those categories to be mutually exclusive. Survival is significantly poorer in those with severe disability. Severe cognitive, motor (manual and ambulatory), and visual disabilities have independent effects on the probability of survival. Severe hearing disability does not add additional information when the other four functional disability categories are included.

See end of article for authors' affiliations

Correspondence to

Correspondence to:
Prof. PO D Pharoah, Department of Public Health, University of Liverpool, Liverpool L69 3GB, UK' p.o.d.pharoah@

liv.ac.uk

Accepted

30 November 2005

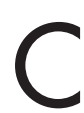
erebral palsy (CP), with a prevalence of 2 to 2.5 per 1000 live births, ${ }^{1}$ is the most common severe physical disability affecting children. The disease has important implications for obstetric and paediatric services and imposes severe stresses and strains on the carers of children who are afflicted. However, unlike the majority of other childhood illnesses, CP also has significant medico-legal implications. To place these implications in perspective, the following statements were made promoting a seminar for legal personnel: damage in cerebral palsy claims average $£ 1$ million each; the cost of birth litigation is at least equal to the cost of running maternity services within the NHS; the identified cost of settlement in cerebral palsy cases is estimated at $£ 60-100$ million. About half of the estimated $£ 430$ million cost of litigation in the NHS relates to claims for cerebral palsy.

A predominant proportion of the total cost of litigation in cases of $\mathrm{CP}$ is the financial settlement awarded to the carers and the determination of quantum is influenced by estimates of future survival. There have been several attempts to estimate the probability of survival of cognitively impaired persons and these estimates will have included some who have CP. ${ }^{2-4}$ Early opinions of survival in CP were generally made by paediatricians, often paediatric neurologists with a specific interest in $\mathrm{CP}$, and were based on clinical experience but without the support of numerical data. In the United Kingdom, reasons why there should be longer term planning for people with cerebral palsy were promulgated in $1990 .{ }^{5}$ Simultaneously an influential paper, based on persons with physical and mental disabilities who received disability services in California, provided actuarial survival data. ${ }^{6}$ Later analyses of the Californian database ${ }^{7}$ and of a health surveillance register in Canada ${ }^{8}$ were limited to children with CP. In addition to these non-disease specific databases, the establishment of population based CP specific registers ${ }^{9-13}$ has provided a considerable body of data that allow the prognosis for survival to be estimated.

The aim of this report is to highlight the issues that have arisen relating to databases used and statistical techniques employed in estimating survival in cases of cerebral palsy that come to litigation.

\section{FACTORS INFLUENCING ESTIMATES OF SURVIVAL IN SEVERE CP \\ Validity of diagnosis of CP}

$\mathrm{CP}$ is a syndrome with more than one pathogenic mechanism. The range of clinical manifestations that may be observed has necessitated a formal definition of the syndrome and several definitions have been proposed. The crucial components of all the definitions are that the impairment: is of the brain; produces disorders of movement or posture; occurs during early development and may be pre-partum, intrapartum, or early post-partum in timing; is nonprogressive; and although non-progressive, the symptoms and signs may vary as the child matures. Any database used for estimating the probability of survival in $\mathrm{CP}$ must exclude all syndromes that have progressive cerebral impairment. Failure to do so may seriously bias the survival estimate. The diagnosis, particularly of severe CP, may be made in the first months after birth but it is essential that later confirmation is obtained. Several conditions, notably neuromuscular disorders, lipoid storage diseases and other metabolic disorders, and cerebral neoplasms may be misdiagnosed as CP during early child development. Failure to exclude these from the analysis will lead to an underestimate of survival. The corollary is also pertinent; motor or developmental problems noted in infancy may subsequently regress. Even a child diagnosed with 
severe cerebral palsy in infancy, may subsequently be shown not to have a disorder of movement or posture. The National Collaborative Perinatal Project in the United States reported that, of the 33 children diagnosed as having severe CP at age 1 year, one was subsequently found not to have the condition at age 7 years and, of the 71 children diagnosed as moderate $\mathrm{CP}$ at age 1 year, as many as 28 were found not to have the condition at age 7 years. ${ }^{14}$ Subsequent confirmation of the diagnosis needs to be made by a paediatrician as failure to substantiate the early diagnosis will lead to an overestimate of the probability of survival.

\section{Severity of functional disability}

Functional disability has usually been categorised into cognitive, motor (manual and mobility), and sensory (vision and hearing) components. Each component may then be further divided into degrees of severity. In an analysis of survival, it is important that each subdivision of severity is clearly defined and that categories are mutually exclusive. If survival in two severity categories does not show a statistically significant difference, the categories should be combined when presenting survival estimates.

\section{Survival analyses according to functional disability}

Table 1 shows the severity categories for the functional disabilities used when estimating survival from the Mersey Cerebral Palsy database when each disability is considered separately. The United Kingdom Collaborative Network of Cerebral Palsy Registers used similar categories with similar results. ${ }^{15}$

Figure 1 shows the survival curves for each of the severe categories of functional disability compared to those whose functional disability was not severe. Several salient observations may be made from Figure 1: the prognosis for survival is significantly worse for the severe compared to the not severe category for each functional disability; for a child who requires a wheelchair for mobility, the survival prognosis is significantly better if the child is able to operate the wheelchair than if totally dependent on the carer to do so; when examined individually, severe ambulatory, manual, and visual disabilities have a worse survival prognosis than severe cognitive disability; and for the visual ability functional category, the group with "possible disability, cannot test or missing" has significantly poorer prognosis than those whose visual disability is not severe. In this context it must be appreciated that the data for the Mersey Cerebral Palsy Register has been obtained from the child's hospital and community health records and is entirely dependent on what the paediatrician has recorded. If the child's visual acuity could not be formally assessed, it is probable that the child's severity of other disabilities made cooperation difficult. Data on visual ability that are "missing" will be so recorded if the child has been lost to follow up or if the child died before formal visual assessment could be made. This category emphasises the importance of quantifying the "missing" data as these data may seriously bias survival estimates. It is reasonable to question why severe visual disability exerts an independent effect on survival when the motor and cognitive disabilities are severe. There is no clear answer but a possible explanation is that coexistent visual disability in $\mathrm{CP}$ is frequently due to cerebral cortical impairment and is an additional marker of the severity of cerebral damage. Within the group of people with severe motor and cognitive disabilities, one quarter have, at most, mild visual disability. This subset is distinct from those with severe visual disability or those whose visual acuity could not be formally assessed. Severe visual disability is more common in CP $(23 \%)$ than severe hearing disability ( $8 \%$ ) (table 1$)$. Hearing disability does not effectively subdivide survival estimates for those with severe cognitive and motor disabilities.

Comparison of survival of those who are severely disabled with those who are not severely disabled in all four functional disability categories is shown in fig 2 . This shows that, from birth, a child who is severely disabled in all four functional disability categories has approximately a $50 \%$ probability of surviving to age 13 years and a $25 \%$ probability of surviving to 30 years. However, an error frequently made is to use such graphs to estimate the survival of a child who is currently alive. This is not valid because it ignores the child's age and even an approximate estimate is likely to be seriously wrong. An individual actuarial analysis using a standard life table approach is required.

\section{Profound or severe disability?}

Profound disability can indicate complete dependence for all activities: that is, it describes a child who is severely disabled in all categories of functional disability. The classification of severity of functional disability used in table 1 has been criticised because it does not distinguish severe from profound disability. ${ }^{16}$ Separation into severe and profound categories of cognitive disability is contentious. In the United Kingdom most children with severe $\mathrm{CP}$, on reaching school age, have an assessment made of special educational need. This assessment usually includes a formal estimation of the child's intelligence quotient (IQ) by an educational psychologist. The ready availability of IQ tests to provide an arithmetic measure of cognitive ability has proved useful in estimating survival in CP and distinction between profound and severe cognitive disability may reveal differences in the probability of survival. However, the precise assessment of IQ

\begin{tabular}{|c|c|c|c|}
\hline $\begin{array}{l}\text { Functional } \\
\text { category }\end{array}$ & Severity level & $\begin{array}{l}\text { Whole cohort } \\
\mathrm{n}(\%)\end{array}$ & $\begin{array}{l}\text { Survivors aged }>2 \text { years } \\
\mathrm{n}(\%)\end{array}$ \\
\hline Cognition & $\begin{array}{l}1 Q \geqslant 50 \\
\mid Q<50\end{array}$ & $\begin{array}{r}1084(66 \%) \\
563(34 \%)\end{array}$ & $\begin{array}{r}1084(68 \%) \\
517(32 \%)\end{array}$ \\
\hline Mobility & Walks, may require aids & $\begin{array}{l}1177(72 \%) \\
86(5 \%)\end{array}$ & $\begin{array}{l}1177(73 \%) \\
86(5 \%)\end{array}$ \\
\hline Manual & $\begin{array}{l}\text { Other wheelchair } \\
\text { Able to feed and dress } \\
\text { Unable to feed and dress }\end{array}$ & $\begin{array}{r}384(23 \%) \\
1265(77 \%) \\
374(23 \%)\end{array}$ & $\begin{array}{r}343(22 \%) \\
1262(79 \%) \\
336(21 \%)\end{array}$ \\
\hline Vision & $\begin{array}{l}\text { None to moderate disability } \\
6 / 60 \text { or worse in better eye, functionally } \\
\text { blind }\end{array}$ & $\begin{array}{l}1283(77 \%) \\
123(7 \%)\end{array}$ & $\begin{array}{l}1279(79 \%) \\
114(7 \%)\end{array}$ \\
\hline Hearing & $\begin{array}{l}\text { Possible disability, unable to assess } \\
\text { None or moderate unilateral disability } \\
\text { Bilateral or severe unilateral disability } \\
\text { Stills to sound or unresponsive }\end{array}$ & $\begin{array}{r}266(16 \%) \\
1538(88 \%) \\
81(5 \%) \\
53(7 \%)\end{array}$ & $\begin{array}{r}233(14 \%) \\
1531(90 \%) \\
81(5 \%) \\
32(5 \%)\end{array}$ \\
\hline
\end{tabular}



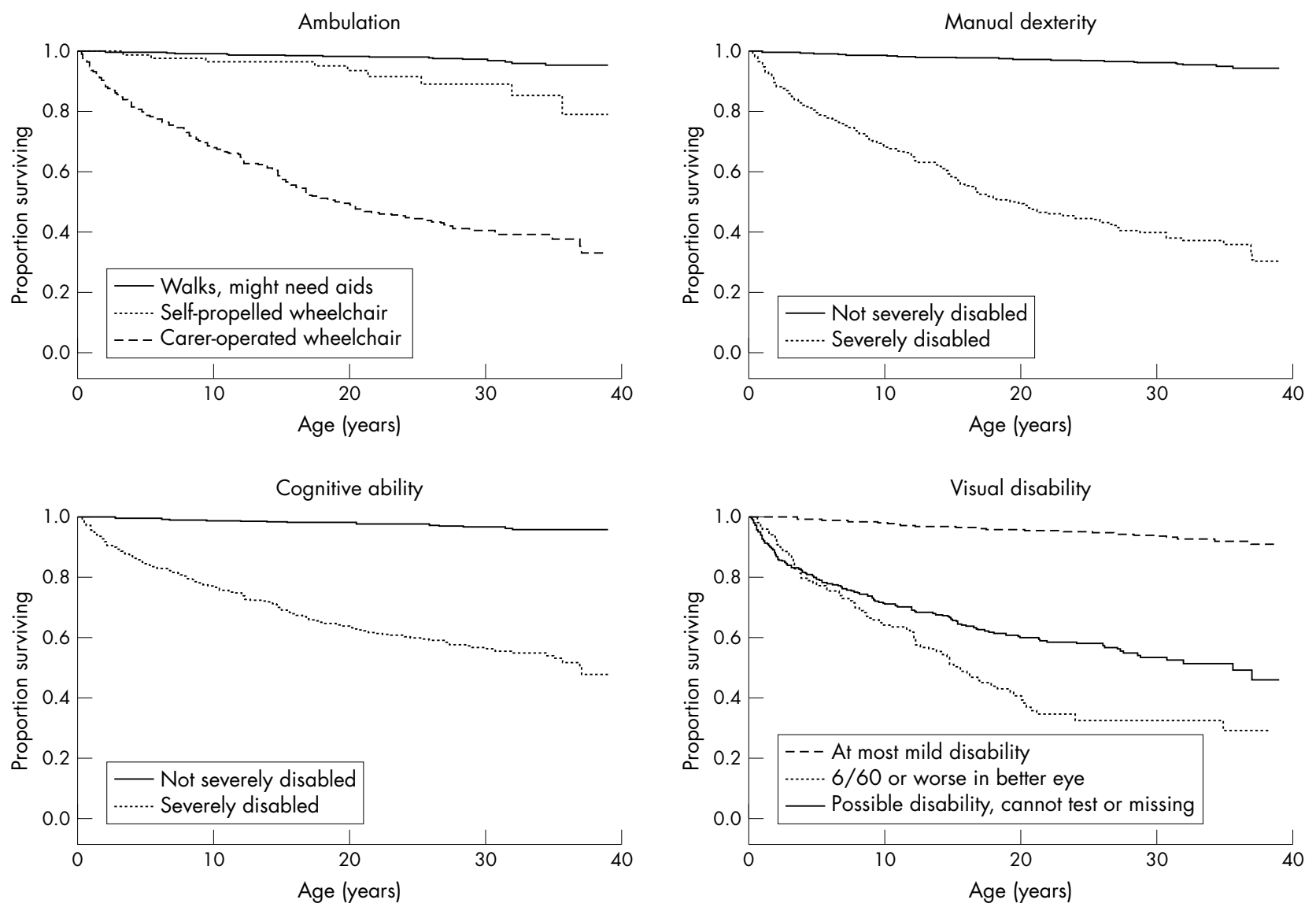

Figure 1 Survival in cerebral palsy by type of functional disability.

in those who have severe cognitive disability, particularly when there are coexistent severe sensory or motor disabilities, is fraught with difficulty. Some differences will occur, depending on what IQ test material is used and on what component of the IQ is being measured, for example verbal or performance components. Any attempt to distinguish the differential effect of severe from profound disability in a single functional domain on an estimate of survival, requires precise and mutually exclusive definitional criteria. It is pertinent that the severity of motor disability, both manual and ambulatory, has greater predictive power than cognitive disability. ${ }^{6}{ }^{9}$ Sub-division of those people with IQ $<50$ may be more reliably achieved by considering other disabilities: of those with severe cognitive disability, only $59 \%$ have severe ambulatory disability and 55\% have severe manual disability. Visual disability provides further sub-divisions.

\section{Other coexistent factors}

In legal proceedings, the effect on survival estimates of other variables such as coexistent epilepsy, the necessity for feeding via a gastrostomy and the possible effect of social and economic circumstances, are frequently raised. Because epilepsy varies enormously in the frequency and type of convulsions that occur and the degree of success in controlling the convulsions, a simple binomial classification that the child either does or does not suffer from epilepsy would be unsatisfactory as a predictor of survival independently from other functional disabilities. Although reclassification of the epilepsy in a hierarchy of severity may possibly be helpful, each category will require precise definitional criteria and each child on the database that is used for estimating survival will need to have the details of the frequency, type, and degree of control of the epilepsy

recorded. Children with $\mathrm{CP}$ who have coexistent generalised epilepsy have a poorer prognosis for survival than those whose epilepsy is unspecified. ${ }^{7}$ However, it is unclear whether the epilepsy has an effect on survival that is independent of the cognitive and motor disabilities and the impact of missing data must be quantified.

The influence on survival of feeding through a gastrostomy may also be contentious. The need for a gastrostomy will be influenced by the clinical assessment of the paediatrician and those who care for the child. On the one hand it is an indicator that the child has severe problems and a poor

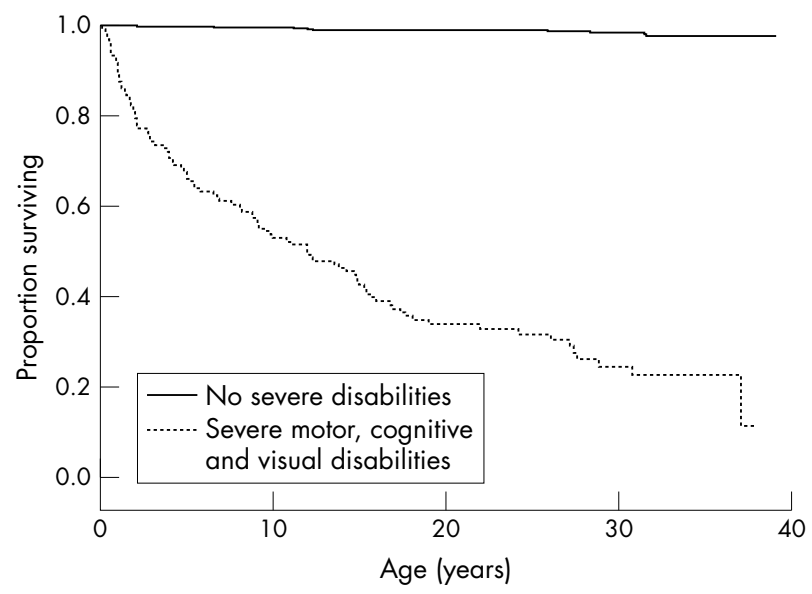

Figure 2 Cerebral palsy survival for mild and severe disabilities. 
prognosis for survival, on the other hand gastrostomy is performed to improve prognosis and quality of life.

It is often claimed that a child with CP from a favourable social and economic environment will have a better prospect for survival than one from an adverse one. However, it could be argued also that the child from an adverse environment, who has been exposed to the infectious and other childhood diseases and survived, has an enhanced probability of additional survival than a child who has yet to meet these vicissitudes of life. As with gastrostomy, the reason for a child being cared for at home or an institution are influenced by the child's condition. The mortality of people with severe cognitive disability living in institutions is usually thought to be greater than those in the community but this has been challenged. ${ }^{17}{ }^{18}$ Recent analysis of survival in CP in the UK reveals a complex interaction between socioeconomic status and birth weight. After allowing for severity of cognitive, motor, and visual disability, the children of normal birth weight $(\geqslant 2500 \mathrm{~g})$ born into affluent families have poorer survival that those from less affluent families. The reverse is true of low birth weight children: an affluent home environment is associated with better survival. ${ }^{15}$ These observations require further analysis, taking into account other factors that affect birth weight. ${ }^{19}$ Unless the distinguishing criteria between favourable and unfavourable home or institutional environments are defined and applied to the database used to estimate survival, it is unwise to resort to intuitive suppositions.

\section{QUALITY OF LIFE IN SEVERE CP}

A Lifestyle Assessment Score (LAS) has been developed to assess the impact of $\mathrm{CP}$ on children and their families using a range $0-100 .{ }^{20}$ A questionnaire yields scores in six dimensions: physical dependency, clinical burden, mobility, schooling, economic burden, and social integration. The LAS combines these scores using weights derived from paediatricians, parents of children with $\mathrm{CP}$, and parents of children without disability. A typical child with LAS of 30 completes most activities alone, poses little economic burden, and attends a mainstream school. A child with LAS of 70 undertakes very few self-help tasks, experiences severe economic difficulties, and is in a specialised educational setting. Although severe disabilities are associated with higher LAS scores, half of those with severe disabilities have LAS scores of less than 70. Survival rates are poorer for those with higher LAS scores.

Lifestyle is associated with quality of life but is not identical. Collaborative work is in progress involving several $\mathrm{CP}$ registers in Europe that is investigating the quality of life in children with $\mathrm{CP}$.

Quality of life for a child with CP will inevitably be affected by quality of care. Although quality of care and its possible effect on survival has featured in legal cases, quality of life has not done so. In settlement of quantum, the compensation awarded will aim at optimising the quality of life.

\section{SURVIVAL ESTIMATES AND CAVEATS WHEN ASSESSING THEIR VALIDITY}

The construction of a life table from which estimates of survival are made is standard actuarial practice. ${ }^{21}$ The table headings are: time interval; number at risk at beginning of the interval; number that died; number censored (a case is censored when the person was alive at last contact but the current fate is unknown because of loss to follow up). For each time period this allows the effective number at risk and the proportion dying to be determined and the probability of survival with its standard error to be estimated. The number censored and the reasons for censoring must be specified as they may influence the validity of the survival estimate. A reliable estimate of survival depends on rigorous follow up of a specified population and valid calculations.

Clinical and actuarial skills are both needed when estimating survival and very few clinicians possess the actuarial skills and an appropriate database to give valid estimates of life expectancy. To our knowledge, the Californian Disability Services Register and the Mersey Cerebral Palsy Register are the only databases that have been used to provide estimates of survival for individuals with cerebral palsy. The pitfalls a clinician may encounter when giving an opinion on survival in cases that come to litigation have been well summarised..$^{22}$ Formal assessments of clinicians' ability to predict life expectancy of terminally ill patients show that clinicians are inaccurate in prognosis even over a few weeks. On average, clinicians gave life expectancies five times greater than the actual life times. ${ }^{23}$ It is unreasonable to expect paediatricians to predict adult life expectancies if they do not follow all the children through into adulthood.

When using different functional disabilities, each with several categories of severity as covariates in estimating survival, the precise combination of covariates must be specified and consistent. It would be possible to reach a wide range of survival estimate by varying the combination of covariates. Also, in any large clinical dataset, it is unusual for every variable to have a complete set of values. The reasons why some values are missing may severely bias a survival estimate. For example, when the intelligence quotient (IQ) is used as a measure of cognitive ability, a missing value for IQ could arise if the child had limited communication and was not assessed for cognitive ability because of other severe impediments.

When life expectancy is quoted, it generally refers to the mean life expectancy, the calculation of which requires every member of the cohort to have died. As with any mean value, it is influenced by whether the frequency distribution of age at death is skewed.

In CP litigation, the usual focus is the median additional life- that is, the additional years before $50 \%$ of the surviving children die. The median can be regarded as the age to which, on balance of probability, a person will live. In financial terms, a mean additional lifetime is the basis for an unbiased estimate of total cost. If median additional life cannot be determined because less than $50 \%$ of the children have died, the probability of survival to a given age with its $95 \%$ confidence interval may be estimated. For a given population, the age limit of the estimation will be determined by the oldest person in the cohort who is currently alive.

Alternatively, survival curves have to be extrapolated and the assumptions made must be specified. For example, at each age, those with cerebral palsy have a higher risk of dying within the next (say one year) time period than the general population. This is known as the age specific risk and can be compared with the general population either as a risk difference or relative risk. The excess age specific risk is the difference between the risk of death in the next year in a person with cerebral palsy at a given age, say aged 20 years, and the general risk of a 20 year old person. The relative risk is the ratio of the risk of death in the next year for a person with CP to the risk of death in the next year for a normal 20 year old. Extrapolations might be based on a constant excess risk at all ages, if the causes of death in $\mathrm{CP}$ are thought to continue to operate throughout life. Alternatively, the age specific relative risk might depend on increasing age (the older the age, the lower the relative risk), possibly in a linear manner. This was suggested for the California database. ${ }^{24}$ One possible reason to expect non-linearity in the change in risk with age is the impact of incapacity or death of the carer of the person with cerebral palsy. At such a time, the person 
with cerebral palsy may show a sharp increase in risk of dying. Analysis of a cohort of persons with CP from Bristol suggests an increased risk of death at about age 50 for the women in the cohort. ${ }^{25}$ Inevitably, any assumptions made are liable to challenge in court. Clinical paediatric, epidemiological, and statistical actuarial expertise are all essential when providing an estimate of survival in CP. Experts in any of these disciplines working in isolation will be open to severe criticism.

\section{Authors' affiliations}

J L Hutton, Department of Statistics, University of Warwick, Coventry, UK P O D Pharoah, Department of Public Health, University of Liverpool, Liverpool, UK

Competing interests: the authors are frequently requested to provide estimates of the probability of survival in cases of cerebral palsy that are the subject of litigation for medical negligence

\section{REFERENCES}

1 Pharoah POD, Cooke T, Johnson MA, et al. Epidemiology of cerebral palsy in England and Scotland, 1984-9. Arch Dis Child Fetal Neonatal Ed 1998;79:F21-5

2 Balakrishnan TR, Wolf LC. Life expectancy of mentally retarded persons in Canadian institutions. Am J Ment Def 1976;80:650-62.

3 Carter G, Jancar J. Mortality in the mentally handicapped: a 50 year survey at the Stone Park group of hospitals (1930-1980). J Ment Def Res 1983:27:143-56.

4 Similä S, von Wendt L, Rantakallio P. Mortality of mentally retarded children to 17 years of age assessed in a prospective one-year birth cohort. J Ment Def Res 1986;30:401-5

5 Evans PM, Evans SJW, Alberman E. Cerebral palsy: why we must plan for survival. Arch Dis Child 1990;65:1329-33.

6 Eyman RK, Grossman HJ, Chaney RH, et al. The life expectancy of profoundly handicapped people with mental retardation. N Engl J Med 1990;323:584-9
7 Strauss DJ, Shavelle RM, Anderson TW. Life expectancy of children with cerebral palsy. Periatr Neurol 1998;18:143-9.

8 Crichton JU, Mackinnon M, White CP. The life expectancy of children with cerebral palsy. Dev Med Child Neurol 1995;37:567-76.

9 Hutton JL, Cooke T, Pharoah POD. Life expectancy in children with cerebral palsy. BMJ 1994;309:431-5.

10 Hutton JL, Pharoah POD. Effects of cognitive, motor, and sensory disabilities on survival in cerebral palsy. Arch Dis Child 2002;86:84-90.

11 Hutton JL, Colver AF, Mackie PC. Effect of severity of disability on survival in north east England cerebral palsy cohort. Arch Dis Child 2000;83:468-74.

12 Blair E, Watson L, Badawi N, et al. Life expectancy among people with cerebral palsy in Western Australia. Dev Med Child Neurol 2001 43:508-15.

13 Williams K, Alberman E. Survival in cerebral palsy: the role of severity and diagnostic labels. Dev Med Child Neurol 1998;40:376-9.

14 Nelson KB, Ellenberg JH. Children who "outgrew" cerebral palsy. Pediatrics 1982;69:529-36.

15 Hemming K, Hutton JL, Colver A, et al. Regional variation in survival of people with cerebral palsy in the United Kingdom. Pediatrics 2005;1 16:1383-90.

16 Rosenbloom L. Estimating life expectancy in children with severe neurological disabilities. Clinical Risk 2004;10:12-13.

17 Strauss D, Kastner DS. Comparative mortality of people with mental retardation in institutions and in the community. Am J Ment Ret 1996; 101:26-40.

18 Zaharia ES, O'Brien K. Mortality: an individual or aggregate variable. Am J Ment Ret 1996; 101:424-9.

19 Wilcox AJ. On the importance and the unimportance of birthweight. Int J Epidemiol 2001;30:1233-41

20 Mackie PC, Jessen EC, Jarvis SN. The lifestyle assessment questionnaire: an instrument to measure the impact of disability on the lives of children with cerebral palsy and their families. Child Care Health Dev 1998;24:473-86.

21 Altman DG. Practical statistics for medical research. London: Chapman \& Hall, 1991.

22 Strauss D, Shavelle R. Doctors are not experts on life expectancy. The Expert Witness 1998;3:11-13

23 Christakis NA, Lamont EB, Smith JL, et al. Extent and determinants of error in doctors' prognoses in terminally ill patients: prospective cohort study. BMJ 2000;320:469-73.

24 Strauss D, Shavelle R. Life expectancy of persons with chronic disabilities. $J$ Insurance Med 1998;30:96-108.

25 Hemming K, Hutton JL, Pharoah POD. Long term survival for a cohort of adults with cerebral palsy. Dev Med Child Neurol. In press.

\section{bmjupdates+}

bmjupdates+ is a unique and free alerting service, designed to keep you up to date with the medical literature that is truly important to your practice.

bmjupdates+ will alert you to important new research and will provide you with the best new evidence concerning important advances in health care, tailored to your medical interests and time demands.

Where does the information come from?

bmjupdates+ applies an expert critical appraisal filter to over 100 top medical journals A panel of over 2000 physicians find the few 'must read' studies for each area of clinical interest

Sign up to receive your tailored email alerts, searching access and more...

www.bmjupdates.com 